\title{
Viscoelastic Properties of 1-Hexene-Propene Copolymers Influence of the Structure and Morphology on the $\beta$ Relaxation
}

\author{
A. Piloz, A. Douillard, J. Y. Decroix, J. F. May, \\ and G. VALLET \\ Laboratoire de Chimie Macromoléculaire associé au C.N.R.S., \\ Université Claude Bernard-LYON I-U.E.R. de Chimie-Biochimie, \\ 43, Boulevard du 11 Novembre 1918-69621-Villeurbanne-France.
}

(Received March 5, 1974)

\begin{abstract}
The dynamic mechanical properties of 1-hexene-propene copolymers were measured in the $\beta$-relaxation range, using a DDV-II Rheovibron viscoelasticimeter. The infrared spectroscopy showed typical bands, from which the copolymer composition could be evaluated and the crystallization ability deduced. The study of the morphology was performed by differential thermal analysis and X-ray diffraction. It led to a model of the copolymers' crystalline structure in which there is still a crystalline fraction up to $60-\%$ 1-hexene concentration (in moles). The experimental results showed that the maximum of $\tan \delta$ shifted towards low temperatures as the 1-hexene concentration increased. Its magnitude grows as the crystallinity decreases. The activation energies associated with relaxation were calculated according to the Arrhenius equation; the average relaxation times were calculated by application of the time-temperature correspondence principle.

KEY WORDS Copolymers 1-Hexene / Morphology / Dynamic

Properties / $\beta$ Relaxation / Activation Energies / Relaxation Times

/ Relaxation Mechanisms /
\end{abstract}

The influence of the number and length of the side chains on the viscoelastic properties $(\beta$ relaxation) in polyethylenes and in $\operatorname{poly}(\alpha-$ olefins) has been reported previously by our laborator ${ }^{1,2}$ and by other laboratories. ${ }^{3-5}$

Following the work already performed on homopolymers, we tried to determine from which molecular mechanisms this relaxation arises in the case of copolymers. Materials composed of propene and 1-hexene were chosen to simplify this investigation. The case of polyhexene had been briefly studied previously and the polymer was proved to be completely amorphous.

The polymerization conditions, the reactivity rates, and the sequences distribution have been reported. ${ }^{6}$ We determined both structural and morphological properties of the copolymers by the usual methods (osmometry, IR spectroscopy, DTA, X-ray analysis) in order to correlate them with the dynamic mechanical properties measured at low frequencies.

\section{PHYSICAL CHEMISTRY CHARACTERIZATION AND MORPHOLOGY}

\section{Characterization}

Molecular Weight. The number-average molecular weight has been determined by means of osmometry. Measurements have been performed on orthodichlorobenzene solutions at $90^{\circ} \mathrm{C}$. The results are shown in Table I. These molecular weights are large enough so that they have no influence on the mechanical properties.

IR Spectroscopy. The different IR spectra were taken at room temperature, using films which were approximately $10^{-1} \mathrm{~mm}$ thick. These films were prepared by moulding, as described in the experimental section. Using this technique, characteristic bands are seen which allow us to evaluate the composition of the copolymers and also give us an indication of the possibility of crystallization.

Polypropene and polyhexene show absorption bands at $995 \mathrm{~cm}^{-1}$ and $720 \mathrm{~cm}^{-1}$, respectively, and thereby can be distinguished. The copoly- 


\section{$\beta$ Relaxation of 1-Hexene-Propene Copolymers}

Table I. Number-average molecular weight $\left(M_{n}\right)$, crystallinity fraction, and evolution

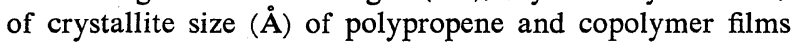

\begin{tabular}{rccccccccccccc}
\hline $\begin{array}{c}\text { Average composition, } \\
\% \text { hexene }\end{array}$ & Polypropene & 8 & 22 & 29 & 35 & 40 & 50 & 63 & 73 & 83 & Polyhexene \\
\hline$M_{n} \times 10^{-5}$ & - & 1.3 & - & 1.0 & 1.6 & 1.5 & 1.5 & 1.6 & 3.6 & 3.1 & 1.6 \\
$X=A_{\mathrm{c}} /\left(A_{\mathrm{c}}+A_{\mathrm{a}}\right), \%$ & 57 & 32 & 30 & 24 & 23 & 25 & - & 10 & & Amorphous \\
Reticular planes $(110)$ & 181 & 123 & 123 & 118 & 132 & 123 & - & 132 & - & - & - \\
& $(040)$ & 192 & 182 & 155 & 148 & 116 & 108 & - & 112 & - & - & - \\
$(130)$ & 233 & 116 & 116 & 90 & 135 & 100 & - & 108 & - & - & - \\
\hline
\end{tabular}

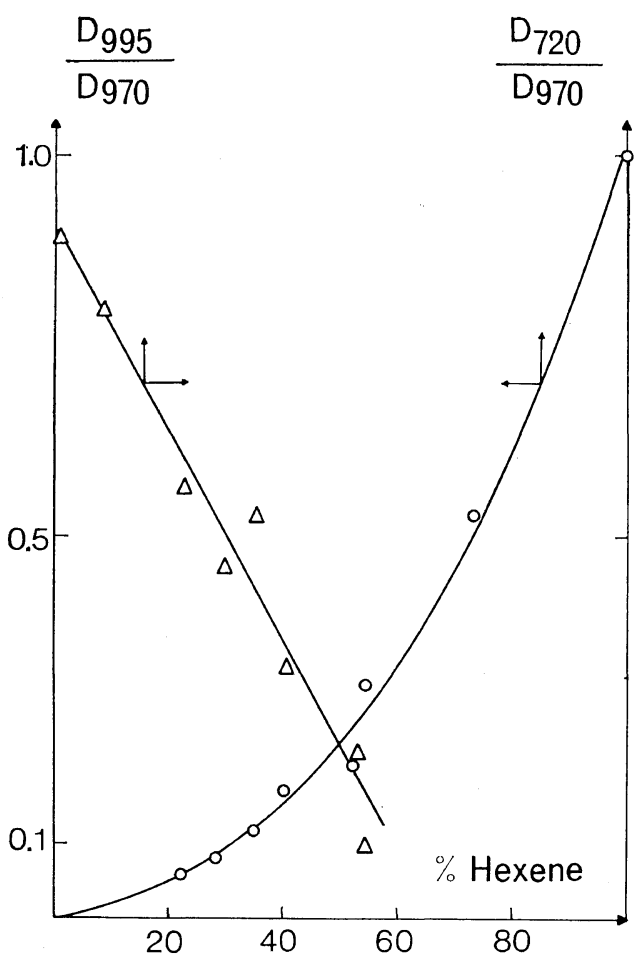

Figure 1. $D\left(995 \mathrm{~cm}^{-1}\right) / D\left(970 \mathrm{c} \mathrm{m}^{-1}\right)$-and $D\left(720 \mathrm{~cm}^{-1}\right) /$ $D\left(970 \mathrm{~cm}^{-1}\right)$-ratio dependences on composition.

mers have a common band at $970 \mathrm{~cm}^{-1}$ with a fairly stable intensity. The ratio $\left[D\left(720 \mathrm{~cm}^{-1}\right) /\right.$ $\left.D\left(970 \mathrm{~cm}^{-1}\right)\right]$ ( $D$ being the optical density) increases with concentration of hexene over the total composition range (Figure 1).

On the other hand, the band at $995 \mathrm{~cm}^{-1}$ provides a means of differentiating the isotactic and atactic fractions of polypropylene. ${ }^{7}$ The values 1 and 0.2 of the ratio have been determined for $100-\%$ isotactic and $100-\%$ atactic polypropene respectively.

In the case of copolymers, this ratio has the

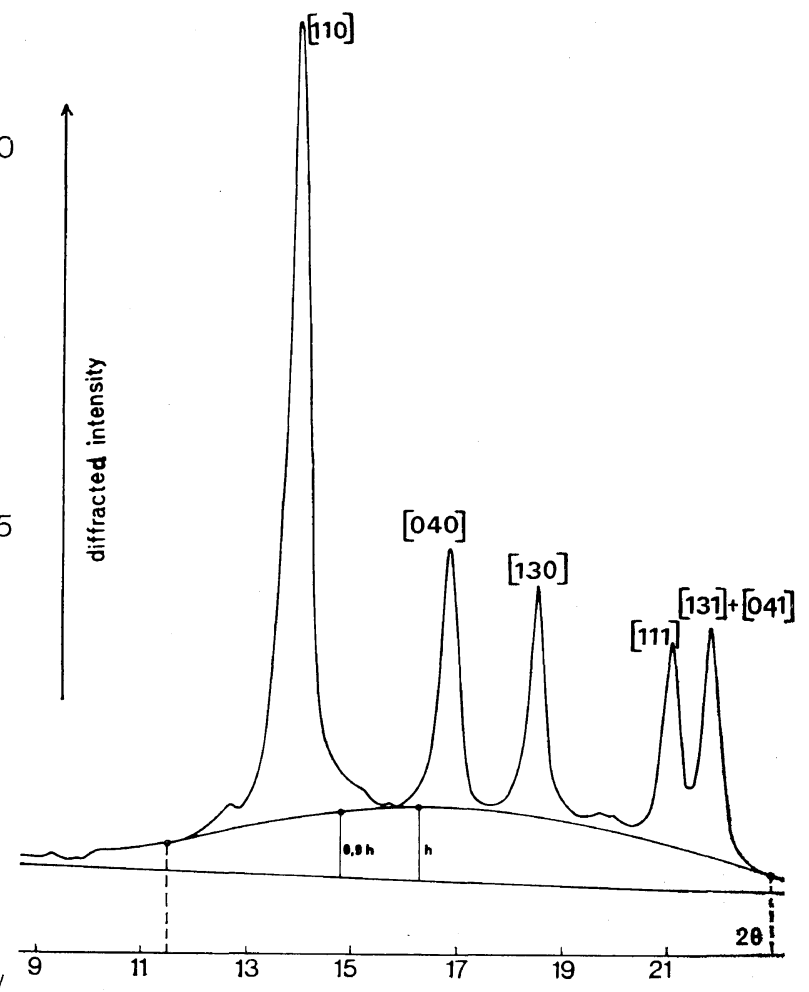

Figure 2. X-ray diffraction pattern of polypropene, showing the surface area attributed to the amorphous regions.

value 0.2 for a $50-\%$ hexene concentration (Figure 1). We can deduce from this value that there is no more isotactic propene and no crystallinity. However this value of 50 per cent must be considered as a minimum, because the contribution of hexene to the $970-\mathrm{cm}^{-1}$ band intensity leads to a decrease of the ratio $D\left(995 \mathrm{~cm}^{-1}\right) / D\left(970 \mathrm{~cm}^{-1}\right)=0.2$ and beyond this value polypropene is completely atactic. 
A. Piloz, A. Douillard, J. Y. Decroix, J. F. May, and G. Vallet

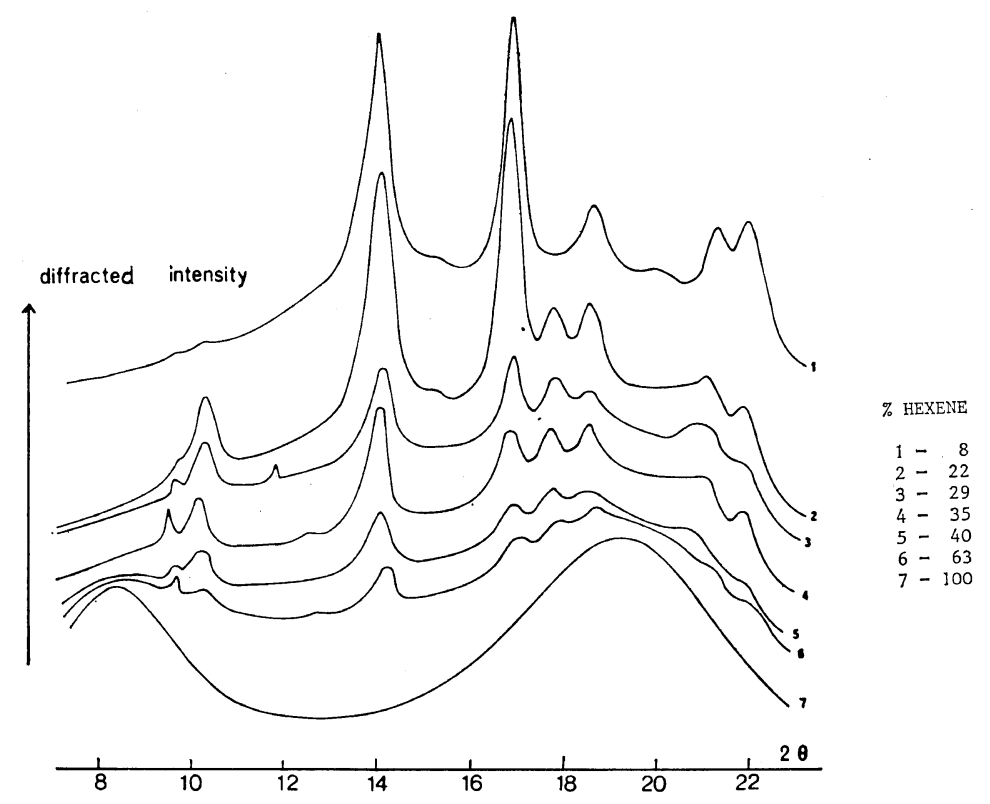

Figure 3. X-ray diffraction patterns of polyhexene and some copolymers.

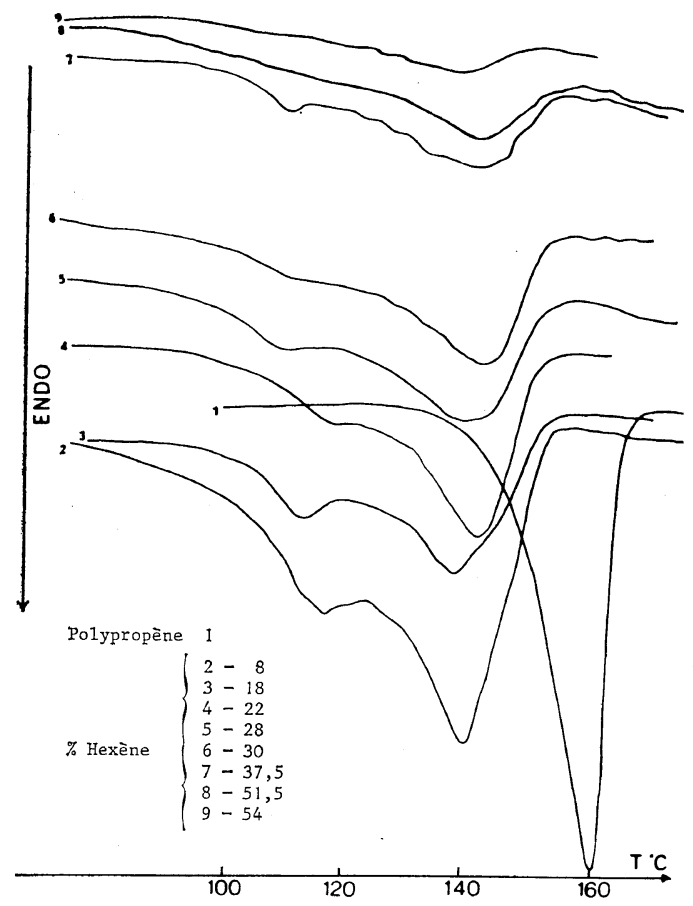

Figure 4. DTA thermograms of polypropene and some copolymers.

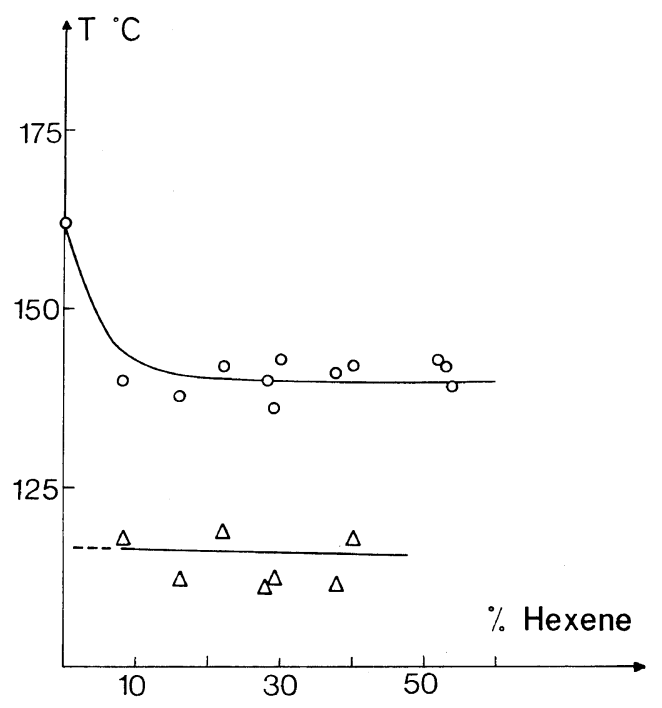

Figure 5. Melting-point dependence on composition. 


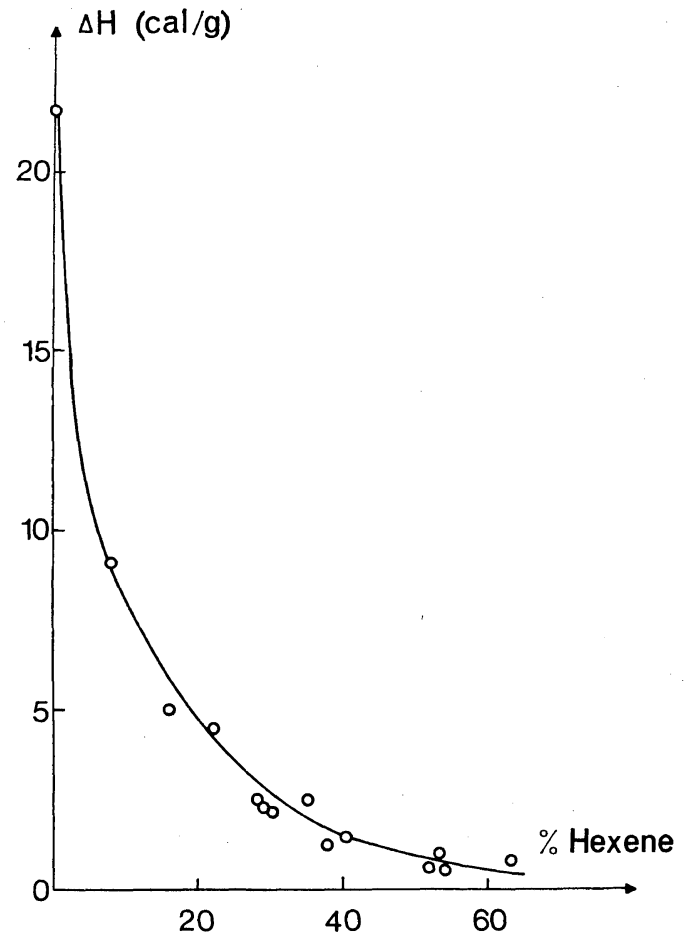

Figure 6. Melting-enthalpy dependence on composition.

\section{Morphology}

Film Preparation. The structural and morphological features have been determined for the films used afterwards for the study of the dynamic mechanical properties. These different films were obtained by moulding under vacuum (i.e. melting, compression, and slow cooling).

$X$-Ray Diffraction. After evaluation of the surface area attributed to amorphous regions on the diffraction patterns (Figures 2 and 3), crystallinity fractions (Table I) were calculated using the approximate relation:

$$
X(\%)=\frac{A_{\mathrm{c}}}{A_{\mathrm{c}}+A_{\mathrm{a}}} \cdot 100
$$

where $A_{\mathrm{c}}$ and $A_{\mathrm{a}}$ are the areas corresponding to the crystalline and amorphous phase, respectively.

The half-height width of the diffraction peaks corresponding to the reticular planes (110) (040) (130) was measured. ${ }^{8}$ By then applying the Scherrer formula, the average dimensions of the crystallites along a direction perpendicular to each plane was calculated (Table I).

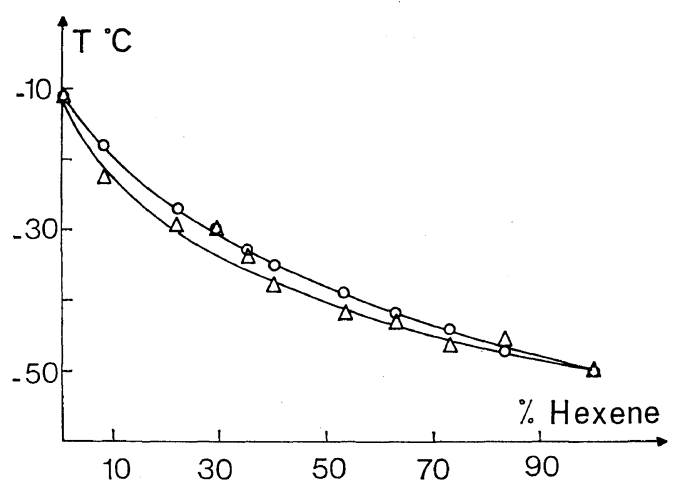

Figure 7. Tangent dependence on composition: $\triangle$, experimental values; $\bigcirc$, calculated values (from the Fox relaxation ${ }^{9}$ ).

Differential Thermal Analysis. Except for polypropene, the thermograms reported on Figure 4 show a double distribution of melting points. The corresponding melting temperature and melting enthalpy calculated from the total area are shown for the apex of the peak in Figures 5 and 6.

In connection with the experimental study the glass-transition temperature of the copolymers has been calculated from the Fox relation ${ }^{9}$

$$
\frac{1}{T_{\mathrm{g}}}=\frac{W_{1}}{T_{\mathrm{g}_{1}}}+\frac{W_{2}}{T_{\mathrm{g}_{2}}}
$$

where $W_{1}$ and $W_{2}$ are the weight fractions of propene and hexene and $T_{\mathrm{g}_{1}}$ and $T_{\mathrm{g}_{2}}$ the glasstransition temperatures of the homopolymers. There is a close agreement between experimental and calculated values (Figure 7).

Discussion. The two melting points (DTA) are most likely attributed to the presence of two crystalline structures. The "high temperature" melting point $\left(139 \pm 3^{\circ} \mathrm{C}\right)$ would correspond to a crystalline structure of polypropene ( $\alpha$ form). However, in order to explain, first, the difference of $20^{\circ} \mathrm{C}$ observed between the melting points of the polypropene and the related copolymers and, secondly, the stability of the melting temperature of these products, it seems necessary to postulate that there has been an insertion of hexene sequences in the structure.

According to Flory's relation ${ }^{10}$ the melting temperature of a copolymer in which only one monomer is able to crystallize is decreased when 
the molar fraction in crystallizable units is lowered.

$$
\frac{1}{T_{\mathrm{m}}}-\frac{1}{T_{\mathrm{m}}^{\circ}}=-\frac{R}{\Delta H_{\mathrm{u}}} \ln p \simeq-\frac{R}{\Delta H_{\mathrm{u}}} \ln X_{\mathrm{c}}
$$

$T_{\mathrm{m}}=$ copolymer melting temperature

$T_{\mathrm{m}}{ }^{\circ}=$ melting temperature of the homopolymer which can crystallize

$R=$ ideal gas constant

$\Delta H_{\mathrm{u}}=$ melting enthalpy per crystallizable monomer unit

$p=$ propagation probability of the crystallizable sequence: For a random copolymer, $p$ takes values close to the molar fraction in crystallizable units $\left(X_{\mathrm{c}}\right)$.

In this study no such effect has been observed. The melting temperature $T_{\mathrm{m}}$ remains stable. The significance of this result could be that $\Delta H_{\mathrm{u}}$ decreases with the molar fraction in propene $\left(X_{\mathrm{c}}\right)$. This variation of $\Delta H_{\mathrm{u}}$ could be due to the insertion of an increasing number of hexene sequences in the crystalline structure.

From the study of the chain stacking in the crystalline phase of polypropene, it seems that such an insertion of isolated and short sequences of hexene $(n=1)$ could be possible without disturbance of the structure. The fall of $20^{\circ} \mathrm{C}$ in the melting temperatures of copolymers compared to polypropene could thus originate from a diminution of the crystallite size; this diminution would be due to long hexene sequences for which no insertion in the crystalline structure is possible. The "low-temperature" melting point $\left(115 \pm 4^{\circ} \mathrm{C}\right)$ could be assigned to a new crystalline structure which would be more compatible with the insertion of longer hexene sequences $(n>1)$. This last hypothesis seems to be corroborated by the appearance of two new unidentified lines in the X-ray patterns, at $d=5.0 \AA$ and $d=8.65 \AA$.

In conclusion, these two techniques allow us to describe the evolution of the crystalline structure of copolymers. For high hexene contents there are mainly isolated and short $(n=1)$ hexene sequences and it seems that these sequences' can be inserted in the polypropene crystalline system ( $\alpha$ form). However, beyond a concentration (ca., 10\%) in hexene we observed a double distribution in melting points (DTA) and new X-ray diffraction peaks result- ing from a new crystalline structure, coexisting with the $\alpha$ form, and more compatible with the insertion of longer hexene sequences $(n=2$ or 3$)$.

\section{MECHANICAL PROPERTIES}

\section{Apparatus}

This study has been carried out with a Rheovibron DDV II viscoelasticimeter designed by M. Takayanagi ${ }^{5}$ and sold by the Toyo Measuring Instrument Company. The elasticity complex modulus $E^{*}$ and the mechanical loss tangent $(\tan \delta)$ can be determined with this apparatus over a large range of temperature $\left(-150-+200^{\circ} \mathrm{C}\right)$ at four different frequencies $(3.5,11,35$ and $110 \mathrm{~Hz})$. A sinusoidal strain of known frequency and amplitude is applied at one end of the test piece; the resulting stress is measured at the other end. The phase displacement angle between strain and stress is the loss angle $\delta$.

\section{Experimental Results}

The maximum of the absorption peak of $\tan \delta$ is shifted towards low temperatures when the hexene concentration is increased (Figure 8). Its amplitude increases as the crystallinity decreases (Figure 9).

The activation energies $\Delta H$ related to the relaxation (Figure 10) have been calculated according to the Arrhenius law:

$$
f=f_{0} \exp \left(-\frac{\Delta H}{R T}\right)
$$

where

$$
\begin{aligned}
f= & \text { measured frequency } \\
f_{0} & =\text { frequency at infinite temperature } \\
T= & \text { temperature of the maximum of } \tan \delta \text { at } \\
& \text { the } f \text { frequency } \\
\Delta H= & \text { activation energy of the motion. }
\end{aligned}
$$

This relation can be applied in a good approximation to the $\beta$ relaxation because of the narrow frequency range which has been studied.

The $\tau$ mean relaxation times related to each polymer have been determined by applying the principle of time-temperature superposition and using a shifting factor $a_{T}$ defined at $T\left({ }^{\circ} \mathrm{K}\right)$ temperature in relation to a $T_{\mathrm{s}}$ temperature, so that $T_{\mathrm{s}}=T_{\mathrm{g}}+50^{\circ} \mathrm{C}\left(T_{\mathrm{g}}=\right.$ glass-transition temperature $)$. Under these conditions the value of $a_{T}$ is: ${ }^{11}$ 
$\beta$ Relaxation of 1-Hexene-Propene Copolymers

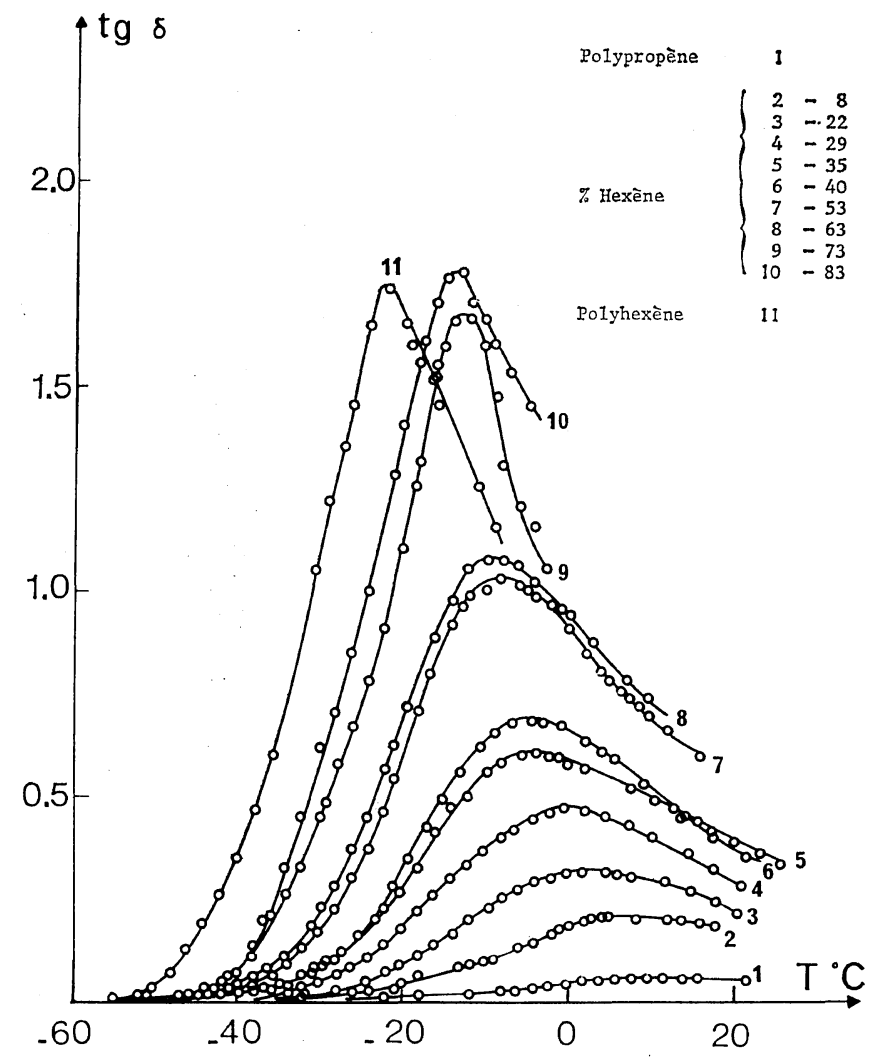

Figure 8. Tan $\delta$ dependence on temperature at $110 \mathrm{~Hz}$.

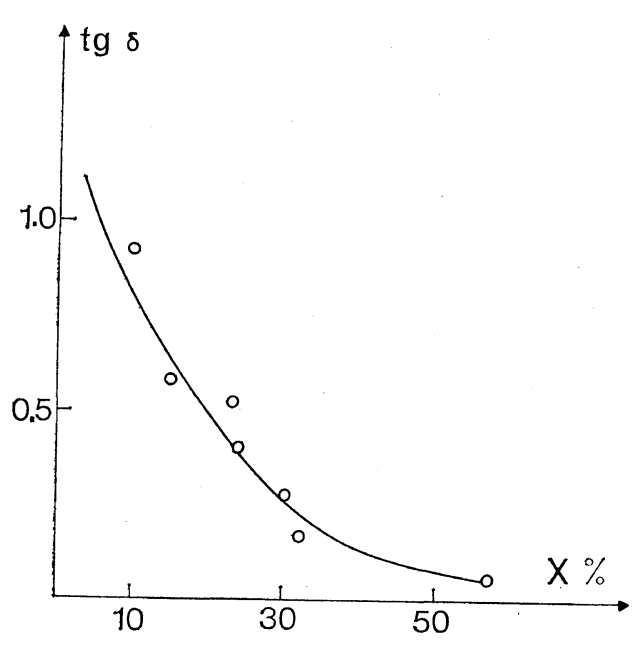

Figure 9. Intensity variation of relaxation peak $v s$. crystallinity degree.

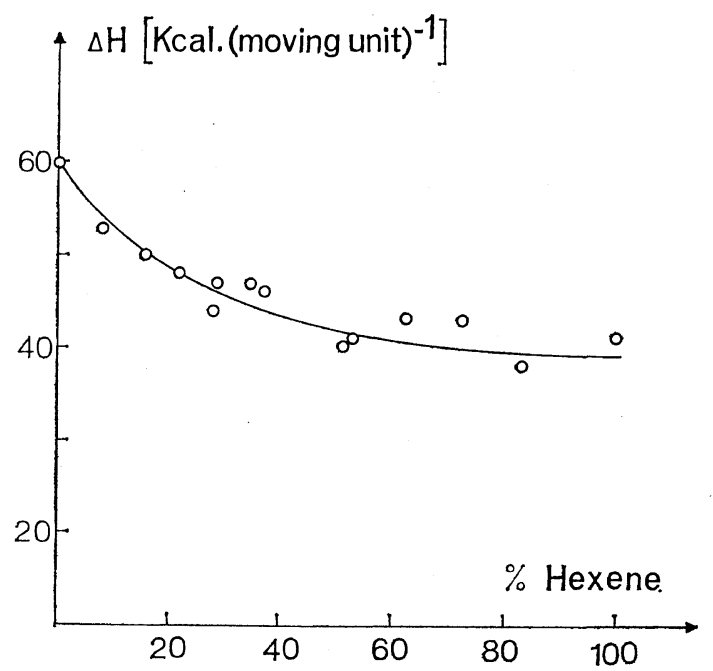

Figure 10. Activation-energies dependence on composition. 

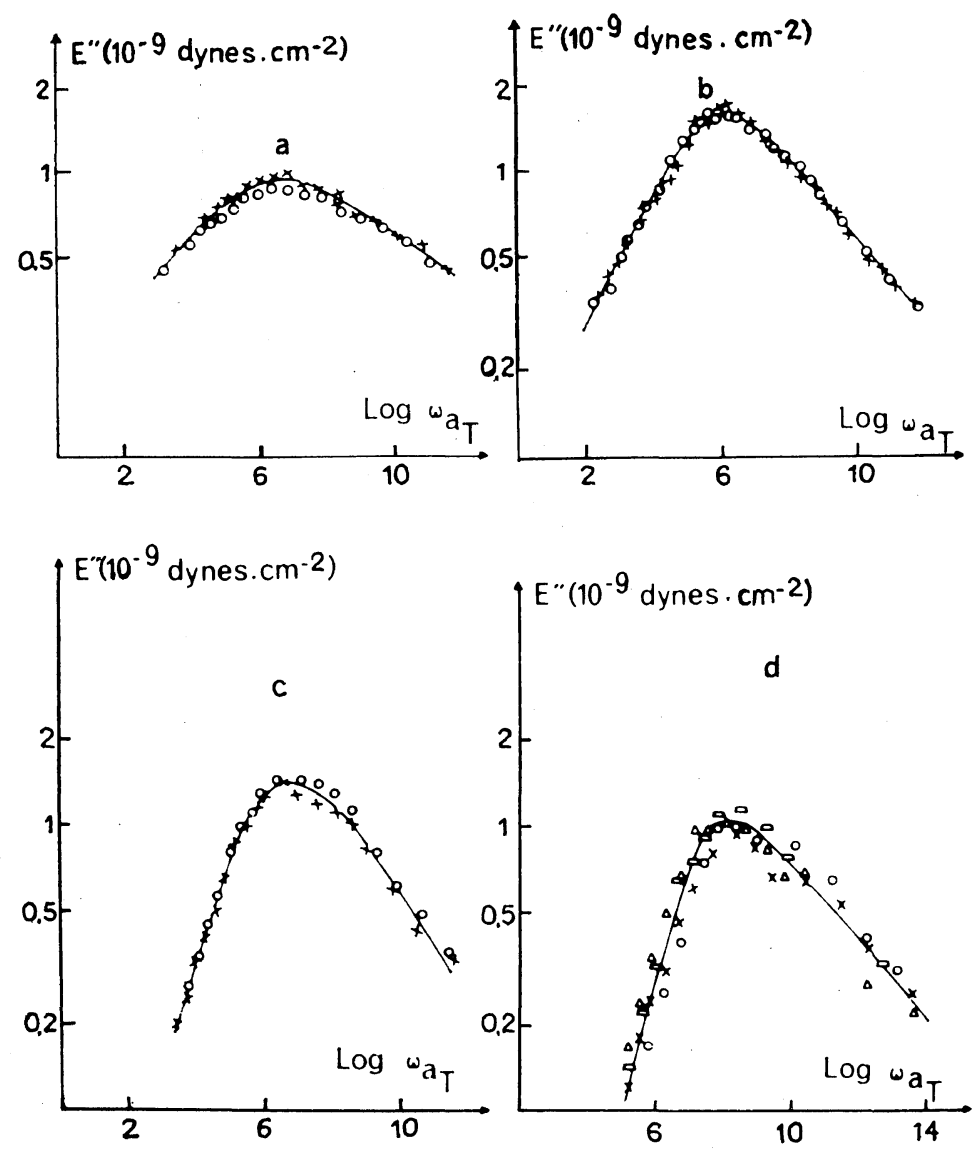

Figure 11. Master absorption curves: a, polypropene, $T_{\mathrm{S}}, 39^{\circ} \mathrm{C} ; \mathrm{b}, 8-\%$ hexene, $T_{\mathrm{s}}$, $27^{\circ} \mathrm{C}$; c, $40-\%$ hexene, $T_{\mathrm{s}}, 12^{\circ} \mathrm{C}$; d, polyhexene, $T_{\mathrm{s}}, 0^{\circ} \mathrm{C}$.

$$
\log _{10} a_{T}=\frac{-8.86\left(T-T_{\mathrm{s}}\right)}{101.6+\left(T-T_{\mathrm{s}}\right)}
$$

The main absorption curves $E^{\prime \prime}=f\left(\log \omega a_{T / T_{\mathrm{S}}}\right)$ (some of them are shown on Figure 11) have been drawn from the isofrequency curves $E^{\prime \prime}=$ $f(T)$. The mean relaxation times are obtained for the $T_{\mathrm{s}}$ temperature using $\omega \tau=1$ at the maximum of the absorption curve ( $\omega$ being the driving frequency). In order to compare the relaxation times $\tau$ and to see how they vary with the copolymer composition, the values of $\tau$ have been determined at diffrent temperatures using the relation $a_{T / T_{\mathrm{s}}}=\tau(T) / \tau_{\mathrm{s}}\left(T_{\mathrm{s}}\right)$, the relaxation times $\tau_{\mathrm{s}}$ at $T_{\mathrm{s}}$ being already known. The dependence of $\tau$ at different temperatures on the copolymer composition is plotted in Figure 12.

\section{DISCUSSION}

We will consider the shifting of the maximum of the absorption peak with temperature, its intensity, the activation energies, and the related relaxation times.

Shifting of the Maximum. In the case of $\left(\mathrm{CH}_{2}-\mathrm{CHR}\right)_{n}$ polyolefins, the relaxation peak is shifted towards low temperatures when the length of the side chain grows. ${ }^{1-3}$ We observed that the copolymers exhibit a similar behaviour when the hexene concentration is increased (i.e., when the average length of the side chain grows).

We have also pointed out an analogous behaviour between the shifting in temperature of the maximum of the $\beta$-relaxation line and the glass-transition temperature. Hence we can relate this relaxation process to the glass transi- 


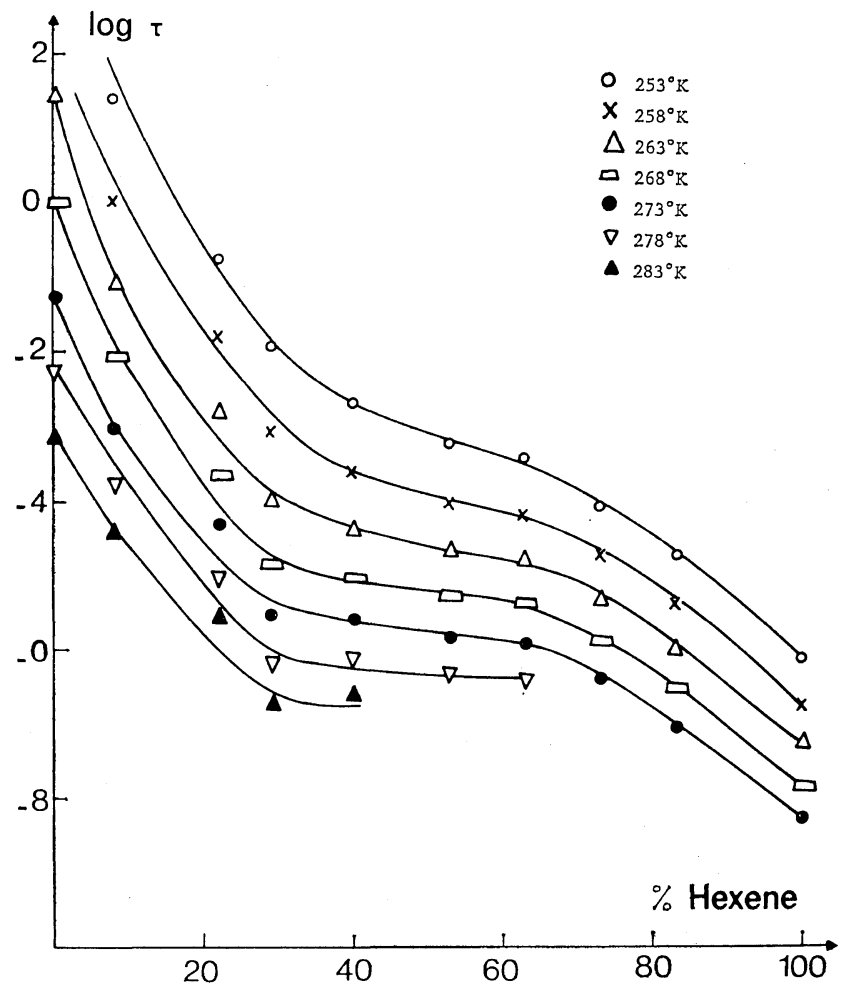

Figure 12. Average relaxation time vs. composition at different temperatures.

tion as usually understood. ${ }^{1}$

The shifting towards low temperatures can be explained by the plasticizing effect due to the side chains, which become longer and more flexible. The energy barrier corresponding to the motion is the sum of two components: ${ }^{12}$ the energy of rotation around the bond; the energy of friction with the surrounding medium. It is this second component which is influenced by the presence of flexible side chains and leads at first to a decrease of the glass-transition temperature. However, beyond a specific size the side chains can arrange themselves inside the sphere. Hence, the change in glass transition $v s$. side-chain size passes through a minimum which is presumably located at a $R$ value above 4 , because no such phenomenon can be observed in Figure 7.

Intensity of the Maximum. As the $\beta$ relaxation can be associated with the glass transition, it is possible to postulate that the relaxation is connected with motion occuring in the amorphous phase; the amplitude of the relaxation peak decreases when the crystallinity increases (Figure 9). The same phenomenon has been observed with polyolefins. ${ }^{1-4}$ The $\beta$ peak remains at the same temperature and its intensity is enhanced when crystallinity is lowered (for the same olefin). These results are in close agreement with the hypotheses which concern the importance of the alkyl group $R$ in $\operatorname{poly}(\alpha-$ olefins). These hypotheses assign the $\beta$ relaxation to a motion of the side chains located in the amorphous phase which spreads to all the main chains of this area. ${ }^{1,2}$ However, it seems more interesting to consider the thermodynamical $(\Delta H)$ and kinetical $(\tau)$ aspects of the phenomenon.

Activation Energy. The activation energy levels out for a $60-\%$ hexene concentration. This dependence, which is analogous to that of the glass-transition temperature, can be explained by the increase of the mean side-chain length which occurs when the hexene content increases. The $\Delta H$ variation could be interpreted first as a diminuation in frictional effects due to an increase of the number of flexible side chains; 
then, as this parameter takes a low energy value, the increase of the steric hindrance would become more important. As this latter factor tends to a limit corresponding to polyhexene, then $\Delta H$ approaches a constant value.

Relaxation Time. One must note a decrease of $\tau$ when passing from polypropene to polyhexene. The vibration of the more numerous flexible side chains produces in an easier fashion a spreading motion of the side chains in the amorphous fraction. However, because of the flat-portion in the curves of $\log \tau v s$. $f$ (hexene $\%$ ), we have been led to amplify the preceding hypothesis. From X-ray diffraction and DTA data, we assumed that there is a new crystalline structure. This structure, because its composition would generate organized zones which contain numerous defects, is formed by the long hexene sequences located between the crystalline lamellae.

On the other hand the calculation of the sequence distribution ${ }^{6}$ shows that, up to $c a$. $25-30-\%$ hexene, there is only a small amount of long hexene sequences $(n>3)$. Thus the number and importance of these defects are limited. At the beginning only the chains in the amorphous part are set in motion. From $30-\%$ up to $65-\%$ hexene (this last value corresponds to the limit of composition which is still compatible with a certain crystallinity) there would be superposition of the general chain motion in the amorphous part and relaxation of the hexene sequences in the defects of the organized region. In this way it would be possible to interpret the unusual shape of the curves of Figure 12 and their change with temperature. The relaxation time associated with the motion of the chain segments in the defects increases with the hexene side group concentration (the steric hindrance increases but there is no more plasticizing effect). On the other hand, as the temperature decreases the side chains in the defects are more and more restrained, which explains the gradual disappearance of the flat portion.

\section{CONCLUSION}

The study of the dynamic mechanical pro- perties has been performed on an apparatus operating at low frequencies. This enabled us to point out the influence of the distribution of methyl and butyl side chains for some 1hexene-propene random copolymers on the $\beta$ relaxation process and to corroborate our former assumptions.

At the beginning (up to ca. 30-\% hexene) the relaxation can be attributed to a generalized motion of the chains in the amorphous region due to the motion of side chains in the same phase. Beyond 30-\% hexene there is superposition of the vibrations of hexene free sequences in the defects of the crystalline part. This phenomenon is shown by our study of the relaxation time $v s$. composition of the copolymer (hexene percentage) and temperature.

Acknowledgements. The authors thank Dr A. Guyot, Directeur de Recherches au Centre National de la Recherche Scientifique, and his coworkers. They are greatly indebted in $\mathrm{Dr} \mathbf{J}$. Guillot for helping during the copolymer synthesis and sequence distribution study.

\section{REFERENCES}

1. P. Lissac, Thèse d'Etat, Lyon, 1970.

2. J. Y. Decroix, P. Lissac, J. F. May, and G. Vallet, Eur. Polym. J., 9, 137 (1973).

3. A. E. Woodward, J. A. Sauer, and R. A. Wall, J. Polym. Sci., 50, 117 (1961).

4. H. A. Flocke, Kolloid Z., 180, 118 (1962).

5. M. Takayanagi, Mem. Fac. Eng. Kyushu Univ., 20 (1963).

6. A. Piloz, Q. T. Pham, J.Y. Decroix, and J. Guillot, J. Macromol. Sci. (Chem.), to be published.

7. J. P. Luongo, J. Appl. Polym. Sci., 3(9), 302 (1960).

8. G. Natta and P. Corradini, Nuovo Cimento, Suppl., 15, 40 (1960).

9. T. G. Fox, Bull. Amer. Phys. Soc., 1, 123 (1956).

10. P. J. Flory, Trans. Faraday Soc., 51, 848 (1965).

11. M. L. Williams, R. F. Landel, and J. D. Ferry, J. Appl. Phys., 26, 359 (1955).

12. A. H. Willbourn, Trans. Faraday Soc., 54, 717 (1958). 